ing produced!" She had printed it from the website where she'd learned how to mix the chemicals.

Since March 2008, more than 180 people have died as a result of inhaling the fumes produced by the deadly mix of common bathroom cleaning products, prompting the Japan National Police Agency to ask Internet service providers to shut down a number of websites that provided a recipe for the toxic gas.

The toxicity of hydrogen sulfide is comparable with that of hydrogen cyanide. It forms a complex bond with iron in the mitochondrial cytochrome enzymes, thereby blocking oxygen from binding and stopping cellular respiration. The victims die from suffocation or brain damage. The hydrogen sulfide gas is colourless and smells like rotten eggs, but it can paralyze the sense of smell after a few inhalations. In lower doses, it causes eye irritation, upset stomach and breathing problems.

Japan has the ninth highest suicide rate in the world. In 2006, 31155 people killed themselves, the ninth consecutive year in which suicide deaths topped 30000 . The government spends \$220 million annually on anti-suicide programs.

According to the World Health Organization (based on 1999 data), Japan had a suicide rate of 24.3 males and 11.5 females per 100000 population. By comparison, Canada's rate was 21.5 and 5.4.

Hajime Oiso, a spokesman for Japan's Ministry of Internal Affairs and Communications, says it isn't clear how many websites have now been shut down or whether that has affected the rate of detergent suicides.

Ontario's Chief Coroner, Dr. Bonita Porter, says there's no evidence the fad has spread to Canada.

But Dr. Paul Links, chair in suicide studies at the University of Toronto, says ready access to information about suicide methods invariably leads to higher rates.

It's not just instructional websites that are a problem, Links says. "In general, there is a relationship between media reporting of method and copycat suicides." — Amanda Truscott, Toronto, Ont.

DOI:10.1503/cmaj.080878

\section{Clowning around sets patients at ease}

$\mathrm{W}$ e've got to walk," says the grandmother, holding her 4year-old granddaughter's hand. Behind them, near the entrance to the cardiology ward of the Hospital for Sick Children (SickKids), trails her 7-year-old grandson.

From under the girl's shirt poke wires and tubes, which lift the fabric off her belly and are attached to a box held by straps in her father's hands.

Her eyes are wide and sad and terrified.

Bunky, a therapeutic clown dressed in blue bloomers, red suspenders and a green shirt, shuffles up and delivers a "thumbs up" to the girl.
She frowns and turns away.

Bunky hauls out green organza, wraps it around his head, bats his eyes and sputters through puckered lips. He sits on the floor and looks up at the children. He smiles and holds up a finger, as if to say: "wait." Reaching to a transparent box mounted on his yellow tricycle, Bunky pulls out a collapsed reticulated sphere and twirls it. The plastic toy expands. It dances on his fingers, spinning and growing. The boy is entranced. Bunky passes him the sphere. It promptly deflates. The boy takes it, twirls it, and it opens again. "Che bella!" exclaims the grandmother, as the girl inches closer for protection.

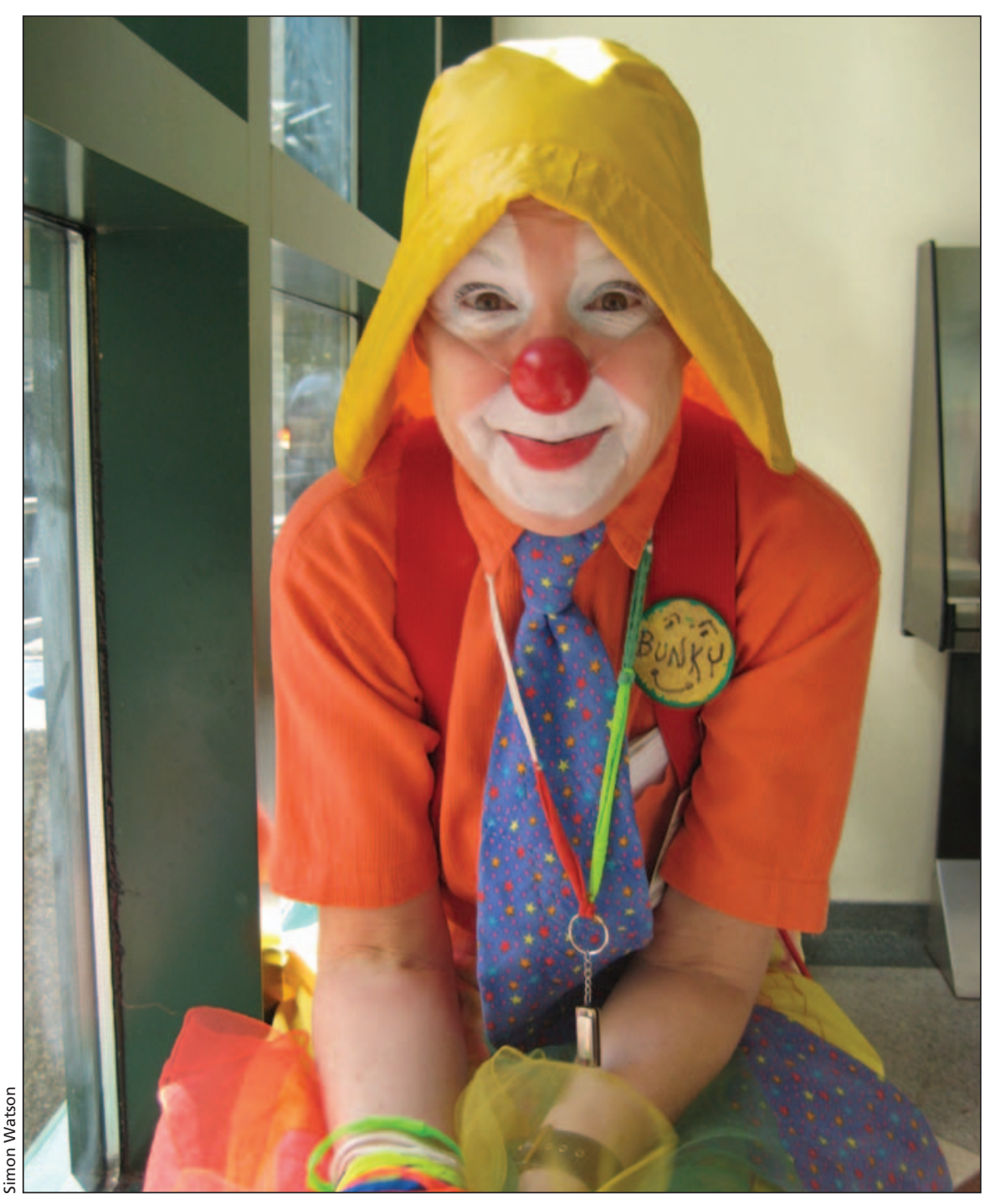

"To be happy and then be sad; sometimes the play is just through the eyes and the smile," says Joan Barrington, a.k.a. Bunky. 
The girl's father and doctor ponder a chart.

"If there's a metabolic imbalance ... need stool sample ... certain bacteria ... issue of low sodium and incidence of epilepsy ...."

Bunky places a picture on the floor. The grandmother picks it up and exclaims, "Ahh, Carmen! Guarda cosa ti ha dato il pagliaccio: un bel disegno da colorare. Digli qualcosa." [Carmen, look at what the clown gave you: a pretty picture to colour. Say something to him."]

Bunky nods, as if comprehending her words.

The girl says nothing. The boy thanks the clown and dashes to grab another toy from the trike.

Bunky shuffles to the playroom door, glances at the girl and gestures for her to enter. She remains pressed to her grandmother's leg. A caretaker walks past, grins, and rings the bell on the trike.

The clown gathers the tools and toys of his trade, gives each child a purple sticker reading "Special Clown Assistant," and mounts the trike. Squeaking, blowing kisses, he wheels down the corridor. The boy yells, "Clowny! Clowny!" and then hides behind a wall. persona is Bunky, seems pensive. "That young girl was cardiac and a lot of
Later, Joan Barrington, whose clown

those patients are afraid to move because they think they'll stop breathing again. A doctor whispered in my ear, asked me to coax the girl and her family out of the room and get her walking. She was still very sad, very motionless. But she was watching everything. And sometimes that's enough."

Barrington established the Therapeutic Clown Program at SickKids in 1993, roughly 6 years after first seeing a newscast about "Robo," Canada's first therapeutic clown, who'd been created at the Winnipeg Children's Hospital in 1986 by Karen Ridd. Informed by SickKids that the program would have to be funded privately, Barrington raised funds to hire Ridd as the program's first therapeutic clown. Months later, Bunky joined the brigade. In the ensuing 15 years, the program has expanded to a clinic of 11 clowns, now seeing 10000 patients per year, and solely funded by donations from individuals, corporations and foundations. Barrington says the cost per clown is $\$ 50000$ per year. Each works 3 days per week and is paid 1 day a month for professional development.

In 1999, Barrington, along with strategic planner Mary Hirst and chartered accountant Heather Spinks created a national organization called Therapeutic Clowns Canada, (which has since dis-

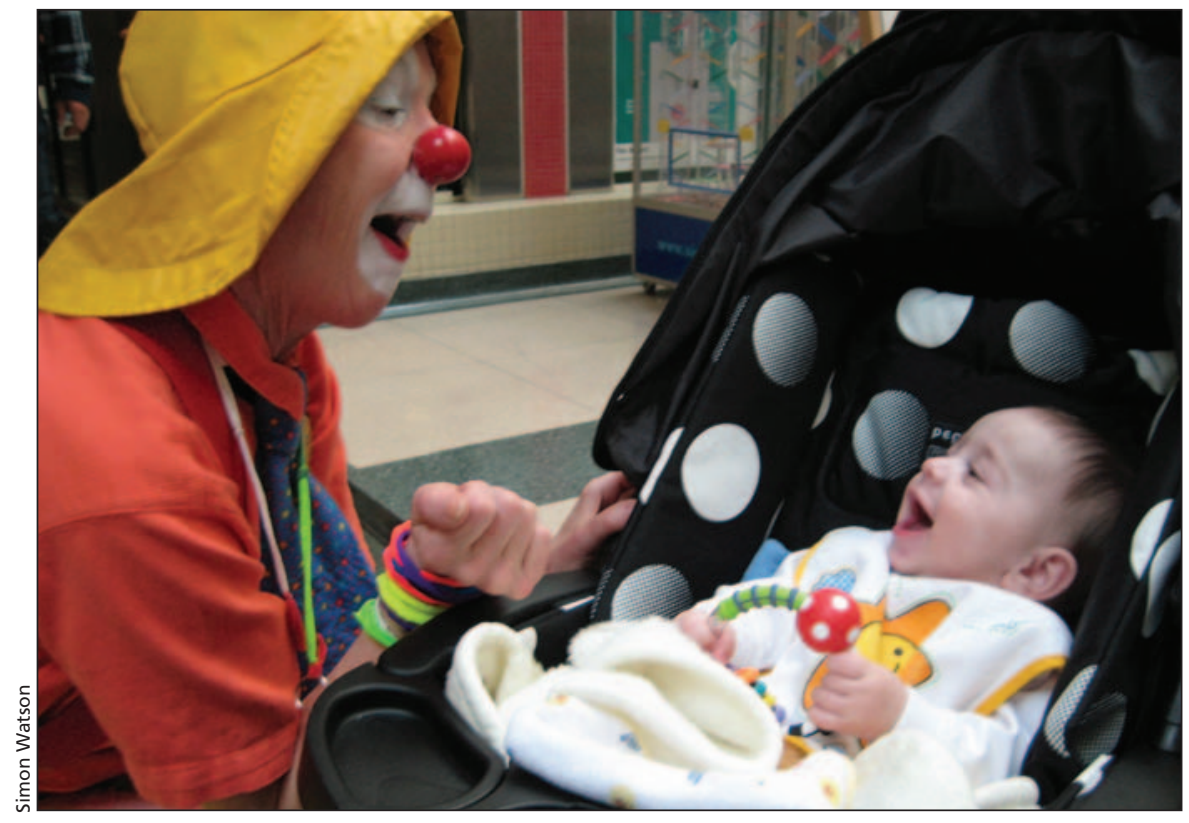

There are now 17 hospitals across Canada with therapeutic clown programs, and the number of pediatric clowns has soared to 52 from 4 since 1999. banded), with a mandate to establish and fund clowning programs in every amenable pediatric facility in Canada, on the proviso that after 2 years, the affiliated hospital would pick up the tab. The number of hospitals with programs has since leapt to 17 from 3 and the number of pediatric clowns to 52 from 4 .

That's an awful lot of clowns, particularly if, as a a recent University of Sheffield study indicated, many children dislike or fear clowns (Nursing Standard 2008;22:11).

But Barrington, who for 15 years served as manager, clown and chief fundraiser for the SickKids program, rejects the notion that 52 Canadians have been given licence to wander pediatric wards and torment ailing youngsters.

Unlike their circus or party cousins, therapeutic clowns don't perform and don't arrive with prepared routines and rehearsed pratfalls, she says. "I'm not there to entertain people. Therapeutic clowning is not about the clown. It's about empowering the children. They don't have any choice over who comes in or out of their room, the doctors who care for them, the illness that they have, or the medications they take. We offer them choices. Always asking permission, we will never go into a room uninvited. If the child says, 'No, I don't want to see you today,' that's great. He can't do that with anyone else. The child leads the play with Bunky."

Bunky makes mistakes, Barrington adds. "He gets into predicaments, and the children help him out of them. They become the caregivers."

Dr. Arlette Lefebvre, a child psychiatrist at SickKids and an associate professor of psychiatry at the University of Toronto, notes that clowns provide children with a sense of mastery over their environment, helping them cope with the physical and emotional stress of being in hospital. "My experience has been very positive with the clowns. They enable the children to feel more comfortable and less scared and that's an important factor in recovery. Anxiety and fear can contribute to pain and slow down participation in recovery."

But Donna Koller, a clinical specialist in SickKids' department of child life, says "there are still people who are challenged by the clown in the hospital 
environment. Serious things happen here, right? And clowns are a contradiction for many. So people are forced to think about health care in a more holistic way. It's not just about giving the right meds and doing surgical procedures but also about the emotional needs that sick children have."

The aim is to use play and laughter as a therapeutic means of relieving stress for patients, families and staff alike, while offering friendship in an unfamiliar hospital environment, explains Sarah Patterson, a specialist in the Child Life Department at SickKids. "When the children in the playroom hear Bunky's horn coming down the corridor their eyes light up. The unit suddenly becomes this uplifting, bright place. You can see it in the faces of the parents, too. All of a sudden their child is a child again, playing like a child and smiling."

Librarian turned therapeutic clown Camilla Gryski describes it as a natural, intuitive and open profession, despite its cosmetics and costumes. "When you clown, it's the irony that you mask to unmask. You strip away your defences, your faces, so that you live in this vulnerable, very honest place. As Posy, I let things happen to me and go with the flow. Intuitively, I listen and become the kind of clown that the child needs me to be."

Bunky is largely mute because Barrington believes the sophisticated language of adults can be a barrier for some children. "But the conversation can still happen, whether it's through my feet or my eyes or my body language."

SickKids clowns rarely speak in fully formed sentences, if at all, Gryski says. "We overwhelm children with our language so easily. We can waltz around them with our words. I think it's better, by and large, to be quieter."

For many of those clowns, the first trick is learning how to quickly dispel clown phobias, which exist even among doctors and other health care professionals, Barrington says. "They may verbalize it or hide behind their desk or physically disappear because they don't want to make eye contact. And I have to respect that."

Part of the problem, Barrington believes, are over-the-top, in-your-face clowns, the sort of creatures that get too

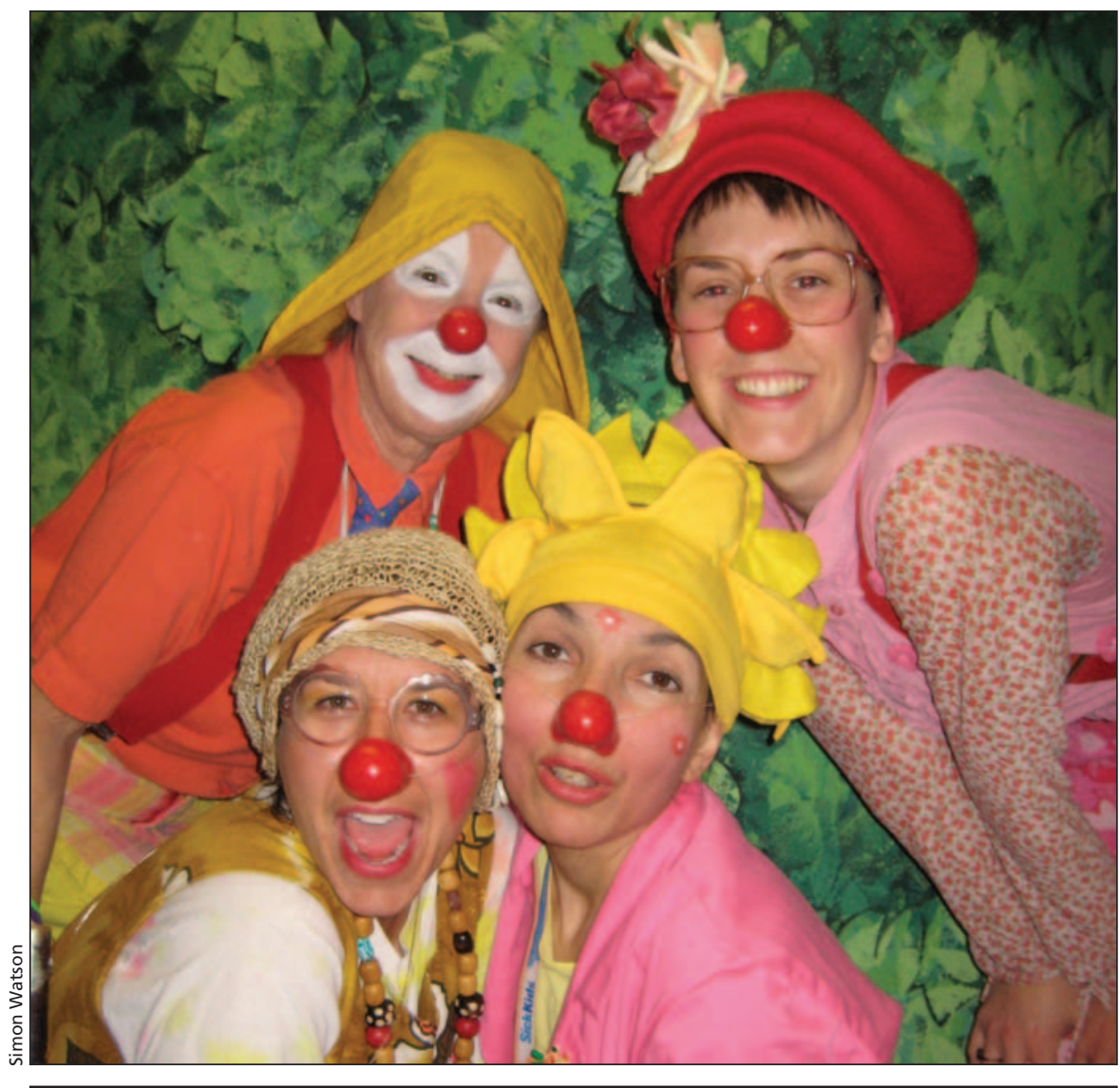

Clowns, clockwise, from upper left: Bunky (Joan Barrington), Rose (Teegan Jones), Nuula (Lucia Cino) and Lubee (Melanie Rosen).

close, too loud, or are too emotionally erratic. "For a lot of people, the clown is that frightening thing behind the mask who's always the bad guy in the movie. The therapeutic clown tries to dispel that prejudice and works towards being gentle and non-invasive. Quieter. Peaceful. Less is more." To that end, Barrington now uses less makeup, to ensure that her humanity is still visible and that she is less "monstrous."

Colleague Lucia Cino, whose clown persona is Nuula, has stopped using makeup altogether. "I was getting rashes and bumps, so I went back to how I was originally taught, which is essentially that the clown is the nose. None of the children have questioned it. They still see Nuula because Nuula is still there."

Whether such nuances actually yield a benefit in a pediatric health care setting is scientifically unclear, however. A literature review by Gryski and Koller (Anaesth Analog 1999;88:24356) found little research about the effec- tiveness of therapeutic clowning except for 2 pilot studies at the Babies and Children's Hospital at the ColumbiaPresbyterian Medical Centre in New York City, New York, which recorded decreases in observed child distress, in child self-reported distress and parentrelated distress during cardiac catheterization when a clown was present. As a result, physicians found the procedure significantly easier to perform. Clown interventions were non-toxic, did not cause respiratory depression, sedation or gastric upset. In addition, positive changes in the behaviour and mood of health care providers were observed when the clowns were "on duty."

Koller says that "clowns induce a great sense of well-being based on humour and laughter. Through play, they allow children to leave the hospital setting and imagine themselves in another kind of imaginary place." - Simon Watson, Toronto, Ont.

DOI:10.1503/cmaj.080691 